\title{
Research on the Standard of Site Management Fee Claim for Schedule Delay Based on Engineering Construction Contract (2013)
}

\author{
Bu Wenxiu ${ }^{1}$ and Ke Hong ${ }^{2}$ \\ ${ }^{1,2}$ School of Management, Tianjin University of Technology, Tianjin, China \\ 1297798835@qq.com
}

Keywords: delay of construction period; site management fee; claim

\begin{abstract}
Currently, the disputes on expense claim problems caused by delay of construction period between the employer and contractor in the project is very common. Such situation can be caused by lacking of clear standards on expense claim problems between the employers and contractors. For the above phenomenon, through literature research and combination with the engineering construction contract (model text)(13 list), this paper divides the factors that influence delay of construction period and analyzes the construction of the site management fee claim for schedule delay, then researches the calculation method of the site management fees, which is beneficial to solve the problems caused by delay of construction period effectively.
\end{abstract}

\section{Introduction}

Project delay is a common problem in the word construction industry today. It is an important reason leading to runaway in progress rate, quality, investment and dispute in the related aspects, and has great influences upon the social and economic benefits of the construction project[1].The management expense claims caused by the delay of construction period is the focus of disputing between the both sides of the contract, and the dispute on the site management fee claim for schedule delay occupies a large proportion. It has an important influence on the quality and economic benefits of the project that site management expenses claims is handled properly or not, which is the premise to reduce the contract disputes between both sides of the contract. Therefore, it is necessary to study the standard of site management fee claim for schedule delay, in order to maintain the interests of both parties.

\section{Study on the construction of site management fee claim for schedule delay}

\subsection{Division of responsibility for the delay of construction period}

When a construction contract is signed by the two sides, the contract period will have a limited influence on them. Contractor must organize the progress construction according to the provisions of the agreement, otherwise, the contractor must understand the loss of delay. The employer also provide site construction conditions for the contractors according to the contract, to ensure the project proceeding smoothly ${ }^{[2]}$. In order to divide and illustrate the responsibility duty in the process of engineering construction clearly, this paper divide the reasons into six aspects from the point of view of the responsible person of the type of delay, namely: the cause of the employer, the contractor, the designer, the supplier, the government. As the parties to a contract, their default is summarized as the breach of contract. In the process of the engineering claims, the responsible person only has two categories: the employer and contractor, that is, the parties to sign the contract. There are only two aspects in the case of claims. Therefore, it can be simply divided into the reason of the employer, the reason of the contractor and the objective reason based on the delay of the above categories, as shown in Figure 2.1. 


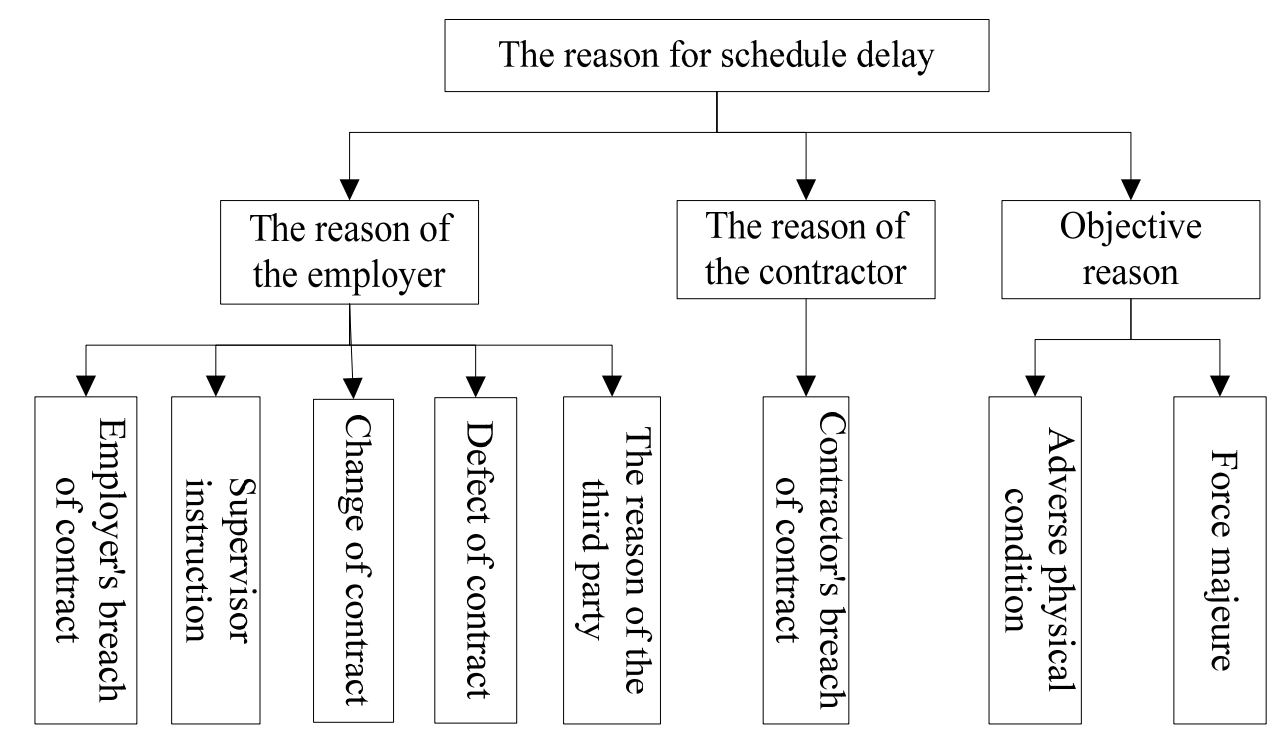

Fig.2.1Factors Affecting the Duration of a Project

\subsection{The basic composition of the site management fee}

\subsubsection{Meaning of the site management fee}

Site management fees can be referred to as the work site management fees, refers to the additional works completed by construction unit or project in the period of delay caused by the cause of the non-contractor, which is the Cost of site organization and management. It accounts for $5 \%-10 \%$ of the total project cost generally, including communication expenses, office expenses, temporary facilities, site management and related service personnel's wages ${ }^{[3]}$. In the process of the actual project expenses claim, the dispute on site management expenses claim is much larger. Therefore, it is the key to be familiar with the composition of the site management fee and choose the appropriate calculation method of site management fee for contractor, which is beneficial to reduce the disputes and improve the success rate of solving the site management fee claim.

\subsubsection{The composition of the site management fee}

For site management fees, the literature researchers divided the site management fees in two different ways. One is divided according to the variable part and the fixed part, the other is divided according to the time correlation, the engineering quantity correlation and the fixed type[4]. The two types are based on the division methods of Construction and installation cost before 2013, having some shortcomings, so this paper adjust the division of the site management fees according to construction and installation cost of the project to build the project 44 [2013]. The consists of the management fee have changed, the employee welfare in the labor cost, the inspection fee in the material cost, and the finance charge increased to management fees. According to the meaning of the site management fee, the site employee benefit is included in the site management fee, the specific content as shown in Figure 2.2. 


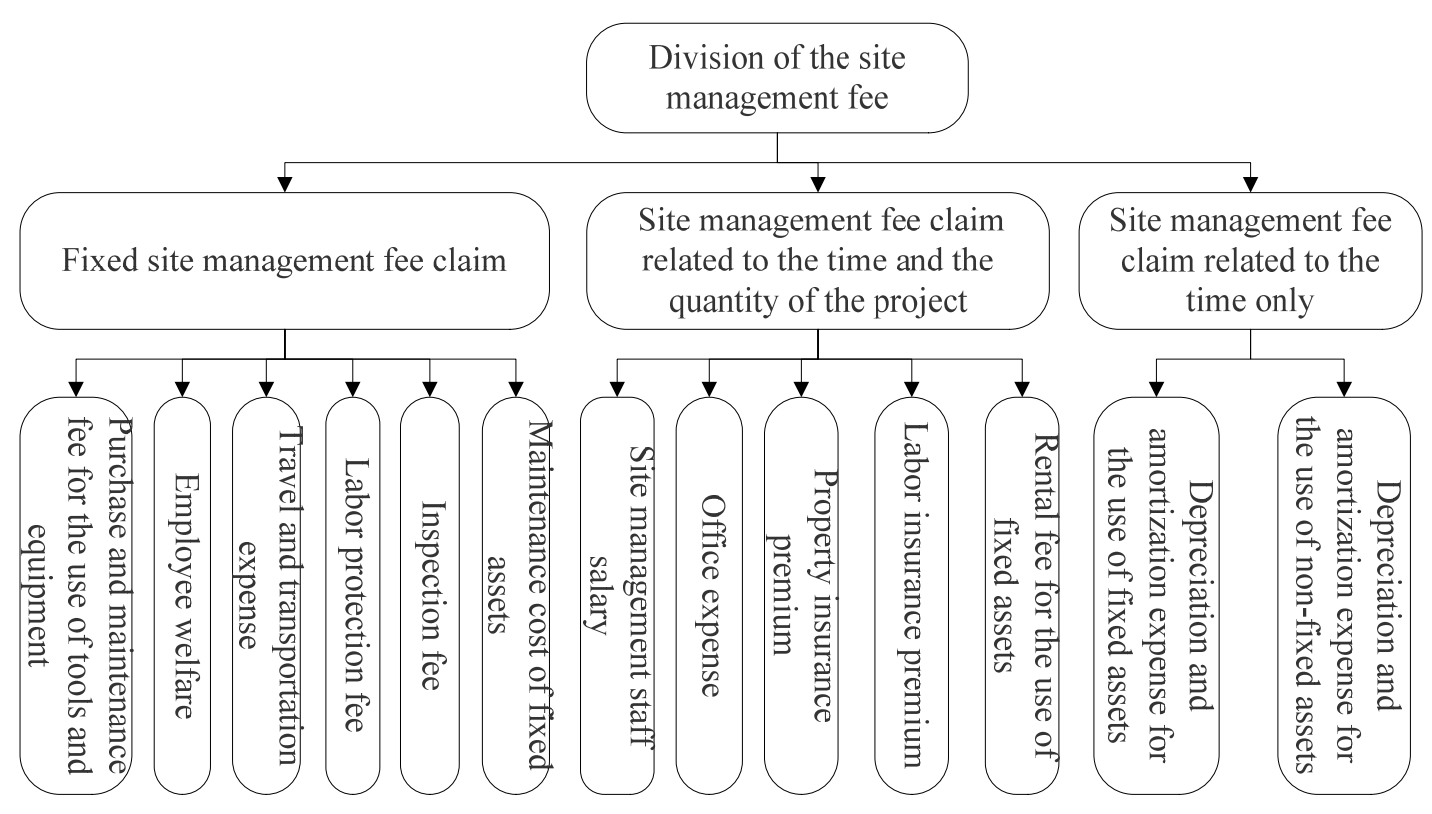

Fig.2.2 Division of Field Management Fees

\section{Calculation of the site management fee Calculation}

\subsection{Research on calculation method of site management fee}

The viewpoint about the calculation method of site management fee in our country is in constant development. The Zhu Xingyu and Wang Xiuqin[5]put forward three ways about the calculation method of international project site management fee, calculating based on the direct cost of claims, calculating the site management fees through the unit time and subentry calculating. They also analyze the advantages and disadvantages of the three methods and the applicable conditions, providing a theoretical basis for further study of the site management fee for domestic researchers. The researcher Zhao Jinxi[6] gives further instruction about the determination of parameters for calculation of site management fee. He thinks that the method for determining the site management fee is percentage method generally when drawing up the engineering budget, engineering bidding price and bidding quotation. The construction engineering, municipal engineering and garden engineering obtain the site management fee based on the direct cost multiplied by a certain percentage. The decoration engineering and installation engineering obtain the site management fee based on the labor cost multiplied by a certain percentage. According to the construction and installation project cost released in 2013, the direct cost is replaced by the sum by labor cost, material cost and engineering cost of equipment. Therefore, this paper will give a new calculation method of site management fee.

\subsection{Subentry calculating method of site management fee}

(1) Fixed site management fee

Fixed site management fee is not related to the time of delay and increased engineering quantity. As long as it is possible to prove that there is such a loss, it is possible to lodge a claim against the employer during the delay period. Therefore, it is necessary to list the specific fixed site management fees in the claim list, which is not calculated. According to the content of 44, the fixed site management fees include the following categories:

1)Purchase and maintenance fee for the use of tools and equipment

It refers to the expense for the acquisition, maintenance and amortization of production tools, appliances, furniture, transportation tools and inspection, testing, surveying and mapping, fire fighting equipment, not belonging to the fixed asset. The calculation formula is as follows.

Tools and equipment usage fee $=$ Purchase cost + maintenance cost

2)Employee welfare 
It includes the collective welfare fees, summer cooling, winter heating subsidies, work transport subsidies paid to the field workers by the enterprise. The calculation formula is as follows.

Employee welfare $=$ Summer sunstroke subsidies + winter heating subsidies + transport subsidies

3) Travel and transportation expense

It includes travel expense on a business trip and mobilization work, living allowance, local transportation, meal allowance, labor recruitment fee, inductrial injury medical treatment expenses, the use of site transfer fee as well as management department of transportation of oil, fuel and other expenses. The calculation formula is as follows.

Travel and transportation fee $=$ travel expense + live attendance, meal allowance + transportation fee + medical expense + oil, fuel cost

4)Labor protection fee

It refers to the expenditure on labor protection paid to the site administrator by the enterprise in accordance with the provisions. The calculation formula is as follows.

Labor protection fee $=$ work clothes, gloves and other labor protection supplies + summer cooling beverage purchase fee + health care cost

5)Inspection fee

It includes the cost of general appraisal and inspection on construction and materials, components, and building installations, according to the relevant standards, including the material cost from experimenting. It may also include inspection personnel wages. The calculation formula is as follows.

Inspection fee $=$ inspection personnel wage + experimental material cost + chemical and pharmaceutical cost

6)Maintenance cost of fixed assets

It includes the overhaul, maintenance and other expenses from house, equipment and instrument belonging to fixed assets that is used by the management and test department and subsidiary production unit. The calculation formula is as follows.

Maintenance cost of fixed assets $=$ overhaul cost + maintenance fee + repair staff salary

(2)Site management fee claim related to the time and the quantity of the project

Whether the site management fee is related to the time or engineering quantity changes, they belong to variable type of site management fee. They all make the corresponding claim calculation with the extension of time or increase in engineering quantity. The calculation principle is that the site management cost of unit time or unit engineering quantity is multiplied by delay time or increased engineering quantity. If it involves the principle of responsibility, it will be multiplied by the share proportion of the responsibility, and the corresponding site management fee is obtained finally. Each specific item of the site management fee that can be claimed is calculated as follows.

1)Site management staff salary

It includes hourly wage, overtime pay and pay under special circumstances paid to the site management. The cost claim is related to the delay time and the increase in engineering quantity. The calculation formula is as follows.

Site management staff salary = hourly wage + overtime pay + pay under special circumstances

a. Hourly wage: Schedule delay makes a lot of work be finished backward. During the delay period, labor wages may rise and labor may increase, so the hourly wage of unit time needs to be calculated in accordance with the new standard.

Hourly wage $=$ labor quantity during the delay period $\times$ rising wage of unit time

b. Overtime pay: In order to speed up the construction progress during the period of delay period, the employer may require the contractor to spend more time than the legal time, and the contractor can claim for the cost.

Overtime pay $=$ overtime work $\times$ overtime compensation of unit time

2)Office expense

It includes the cost of stationery, paper, table accounts, printing, post and telecommunications, newspapers, office software, on-site monitoring, meeting, water, electricity, heating water and on- 
site dormitories temporary heating and cooling from the site management office. The calculation formula is as follows.

Office expense $=$ basic cost + Price rising cost

Basic cost: During the delay period, the office expenses in the construction site will be increased with the increase of the amount of use. It still can be calculated in accordance with the formula that quantity is multiplied by price, and the quantity is the amount of change compared with no delay.

Price rising cost: During the delay period, the price level will rise, so the contractor can claim for the cost of growth.

Price rising cost $=($ consumption after the delay -consumption before the delay $) \times($ price after rising - price before rising )

3)Property insurance premium

It refers to the insurance cost for the property, vehicle and so on. During the delay period, the contractor will increase the cost of insurance if the property or the number of vehicles increase because of the project construction. The property insurance premium will increase if the cost of insurance rises during the delay period. Because of the limited research, the following formula doesn't take the factors of price increasing into account. The calculation formula is as follows.

Property insurance premium $=($ total property insurance premium specified in the contract $/$ total duration ) $\times$ delay time

4)Labor insurance premium

It refers to insurance cost paid by enterprises in order to protect the safety of workers in the field of construction when constructors are injured in the construction site. In general, it is calculated according to the number of people and the insured amount of each person. Labor insurance premiums may increases as the increasing of price and the amount of labor during the delay period. The calculation formula is as follows.

Labor insurance premium $=$ number of construction + insurance cost per person

5) Rental fee for the use of fixed assets

It refers to rental fee from house, equipment and instrument belonging to fixed assets that is used by the management and test department and subsidiary production unit. The following formula does not take into account the increase in usage of equipment, instrument and so on .The calculation formula is as follows.

Rental fee for the use of fixed asset $=$ rental fee of unit time $\times$ delay time

\section{(3)Site management fee claim related to the time only}

The cost related to the time only refers to the depreciation and amortization expense of fixed assets or non-fixed assets generally. The methods of calculating the depreciation expense consist of the straight line method, unit of production method, $m$ double declining balance method and the sum of the years digits method. Considering the factors in many aspects, this paper argues that it's reasonable to calculate the depreciation and amortization expense of fixed asset or non fixed asset using the double declining balance method.

1)Depreciation and amortization expense for the use of fixed assets

Yearly depreciation of fixed assets $=$ (the life of the remaining years/Estimated life expectancy $)$ $\times 100 \%$

Monthly depreciation of fixed assets $=$ (asset price - net salvage $) \times$ Annual depreciation amount/12

Depreciation and amortization expense for the use of fixed assets $=$ Monthly depreciation of fixed asset $\times$ delay time

2) Depreciation and amortization expense for the use of non-fixed assets

The calculation formula is the same as the depreciation amortization expense for the use of the fixed assets. 


\section{Conclusion}

This paper analyzes the site management fee based on the subentry method. The site management fee is divided into three parts: fixed site management fee claim, site management fee claim related to the time and the quantity of the project and site management fee claim related to the time only. And the calculation formula of each type is also listed clearly. The research of this paper is beneficial to calculate the site management fees more easily for contractor, so as to reduce disputes between the two sides. However, the calculation method for each division of the site management fee may be a little deviation because of lacking of domestic and international research literatures, which is the deficiency of this paper.

\section{References}

[1] Zhang Yunbo. The Study on the Cause of Delay and the Model of Early Warning In Construction Project [D].Tianjin: Tianjin University,2004.

[2] Huang Deqi. Cost Analysis of Project Delay [J].Fujian Science and Technology Building,2007(02):77-78.

[3] Si Xiaoyu, Guo Gang. The calculation and analysis for the site management fee claim[J].Hebei Institute of Architecture and Civil Engineering News,2005,23(02): 121-123.

[4] Wang Jinmin, Shenjie, Cheng hu. The study on the calculation method of the cost of project delay in China[J]. Journal of Southeast University,1998,28(05): 114-118.

[5] Zhu Xingyu, Wang Xiuqin. The study on Claims of International Engineering Project Management Fees[J].International Economic Cooperation, 2009(03): 66-70.

[6]Yin Yilin, Sun tong, Zhao Jinxi. Research on the Cost Structure System under the Mode of Valuation with Bill of Quantities [J]. Construction Economy, 2012(08): 60-63. 